\title{
Analysis of hazardous processes in the natural-industrial system
}

\author{
I.I. Bosikov \\ PhD in Engineering sciences, Associate Professor, North-Caucasian Institute of mining and metallurgy \\ (State Technological University), Vladikavkaz, Russia
}

\author{
R.V. Klyuev \\ Grand PhD in Engineering sciences, Head of (the) Department, North-Caucasian Institute of mining \\ and metallurgy (State Technological University), Vladikavkaz, professor, Moscow polytechnic university, \\ Moscow, Russia \\ Yu.V. Dmitrak \\ Grand PhD in Engineering sciences, rector, North-Caucasian Institute of mining and metallurgy (State \\ Technological University), Vladikavkaz, Russia
}

\begin{abstract}
The article describes the research and analysis of the occurring hazardous processes in the natural-industrial system and the assessment of the effectiveness of its functioning using mathematical models. Relevance. Studies of the laws governing the functioning of the natural-industrial system are becoming increasingly relevant in connection with the statement of the problem of modernizing the mining and processing industry and the Russian economy as a whole. Due to the significant amount of poorly structured data, it is complicated by the regulations for the effective functioning of production processes, social and natural complexes, which would ensure the sustainable development of the natural-industrial system of the mining and processing complex. Therefore, scientific and applied problems, the solution of which allows us to formalize the hidden structural laws of the functioning of the naturalindustrial system and make managerial decisions of an organizational and technological nature to increase the efficiency of the system's functioning, are very relevant. The purpose of the work: is to study the relationship between the parameters of the teaching staff of the mining and processing complex and the development of methods, criteria, and algorithms for determining effective and safe technologies to ensure the effective functioning of teaching staff. Research methods include mathematical modeling, laboratory and industrial experimental studies, multivariate and regression - correlation analysis. Research results. The obtained criterion in terms of indicators of technological and technogenic factors of the mining and processing complex allows us to evaluate and predict the level of pollution from the territory of the formed dumps. Conclusion The validity and reliability of scientific statements, conclusions and research results are based on the use of leading scientists in the field of system analysis of the technosphere as a theoretical and methodological base, confirming the conformity of the results of theoretical studies and practical information, as well as implementation in production.
\end{abstract}

\section{INTRODUCTION}

The problems of choosing effective and safe technologies using methods, models and criteria that describe complex technical systems are developed in the works of domestic and foreign scientists: B.Ya. Sovetova, S.A. Yakovleva, A.S. Rykova, P.G. Belova, N.N. Moiseeva A.A. Samarsky, D.N. Khomyakova, D. Neumann, K. Pearson, R. Fisher, A. Wald, Yu.I. Zhuravleva, K.V. Rudakova, V.D. Mazurova, V.P. Maslova, M.A. Aizerman, N.S. Kremer. 
When considering the teaching staff of the mining and processing complex, numerous tasks arise that require an assessment of the quantitative and qualitative regularities of the processes of the functioning of the system. The limited capabilities of the experimental study of teaching staff makes it urgent to develop methods and models that would allow us to represent the processes of the functioning of the system in an appropriate form, a description of the course of these processes using mathematical dependencies, and an assessment of the characteristics of the objects under study.

The questions of studying the laws governing the functioning of teaching staff are becoming more relevant in connection with the statement of the problem of modernizing production and the Russian economy as a whole. In connection with a significant amount of poorly structured data, it is complicated by the regulations for the effective functioning of production processes, social and natural complexes, where sustainable development of teaching staff would be ensured. Therefore, scientific and applied problems, the solution of which allows us to formalize the hidden structural laws of the functioning of teaching staff and make managerial decisions of an organizational and technological nature to increase the efficiency of its functioning, are very relevant.

The authors analyzed the teaching staff of the mining and processing complex of the Dzhezkazgan mining and processing plant: the features of the functioning of the natural-industrial system are examined; dangerous processes that occur in the teaching staff of the mining and processing industry and their modeling features; an analysis of the technologies for mining and processing the useful component, as well as methods for choosing safe technologies; experimental data of studies of the parameters of the teaching staff are presented.

The teaching staff, in fact, is a geographically distributed system, the basic components of which are: people, equipment and the working environment, interconnected by an external (for the whole system) environment using technology. NIS states are determined by the NIS structure, which includes the above components with their relationships, which are considered time-varying variables and together determine the corresponding factor space.

The paper considers the teaching staff, the general view of which is presented in Figure 1.

The input parameters are: emissions into the atmosphere $\left(X_{1}\right)$, discharges into the aquatic environment $\left(X_{2}\right)$, discharges into the lithosphere $\left(X_{3}\right)$, tailings of concentration plants $\left(X_{4}\right)$, household waste $\left(X_{5}\right)$, radioactive waste $\left(X_{6}\right)$, pesticides and toxic chemicals $\left(X_{7}\right)$. The output parameters are: the number of inpatients $\left(Y_{1}\right)$, cancer patients $\left(Y_{2}\right)$, deceased $\left(Y_{3}\right)$, cancer patients $\left(Y_{4}\right)$ and children born with abnormalities $\left(Y_{5}\right)$, the general incidence of NIS $\left(Y_{6}\right)$.

The following are considered as hazardous processes arising in the teaching staff:

- man-caused, associated with the possibility of unwanted emissions of energy and substances accumulated in man-made technological objects (industries);

- anthropogenic, caused by the harmful effects on people of pollutant emissions (pollutants) of the teaching staff of the mining and processing complex.

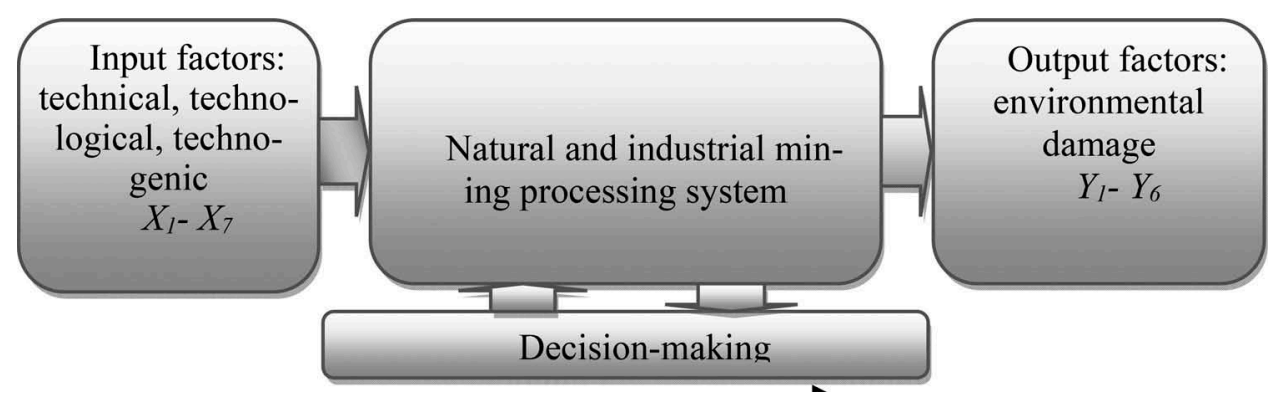

Figure 1. A generalized scheme of the teaching staff of the mining and processing complex. 


\section{INITIAL DATA FOR RESEARCH}

Environmental pollutants in the functioning of natural systems of industrial mining and processing complex are the sources of contaminant's release. The pollution source - the object (production processes, machines, etc.), as well as storage places of bulk or liquid materials, quarries, waste dumps, waste disposal sites, which under the influence of weather and other factors are subtracting contaminants.

The influence of harmful emissions into the atmosphere $\left(X_{1}\right)$, discharges into the aquatic environment $\left(X_{2}\right)$, discharges to surface topography $\left(X_{3}\right)$, the tails of enrichment plants $\left(X_{4}\right)$, municipal waste $\left(X_{5}\right)$, radioactive waste $\left(X_{6}\right)$, pesticides and toxic chemicals $\left(X_{7}\right)$, the number of inpatients $\left(Y_{1}\right)$, cancer patients $\left(Y_{2}\right)$, deceased $\left(Y_{3}\right)$, births $\left(Y_{4}\right)$, children born with abnormalities $\left(Y_{5}\right)$, and the overall incidence of NIS population $\left(Y_{6}\right)$ (Bosikov, Klyuev, Revazov \& Pilieva. 2018), (Yegorova, Klyuev, Bosikov \& Tsidaev. 2018), (Klyuev, Bosikov, Gavrina \& Revazov. 2018).

The ranges used by independent variables varied:

a) in a dimensional scale:

1) $47.142<A<94.285$

2) $11.5<B<23.0$;

3) $131.5<C<394.5$;

4) $3223.7<D<8059.43$;

5) $2750.0<E<6875.0$;

6) $0.011935 .5<F<1935.5$;

7) $0.4<G<0.65$.

b) in a dimensionless scale:

$$
\begin{aligned}
& x_{1}=\frac{A-70.71}{23.575} \mathrm{r} \\
& x_{2}=\frac{\mathrm{B}-17.25}{5.75} \\
& x_{3}=\frac{\mathrm{C}-263.0}{131.5} \\
& x_{4}=\frac{\mathrm{D}-5641.58}{2417.85} \\
& x_{5}=\frac{\mathrm{E}-4812.5}{2062.5} \\
& x_{6}=\frac{\mathrm{F}-967.755}{967.745} \\
& x_{7}=\frac{\mathrm{G}-0.525}{0.125}
\end{aligned}
$$

The influence of harmful substances on the social complex of mining and processing complex (the value $Y_{1}-Y_{5}$ ), with the use of mathematical experiment planning in accordance with the plan shown in Table 1 matrix.

Data processing method of least squares provides a linear regression equation variables $Y_{1}-Y_{5}$ in general form:

$$
Y=b_{0}+b_{1} \cdot x_{1}+b_{2} \cdot x_{2}+b_{3} \cdot x_{3}+b_{4} \cdot x_{4}+b_{4} \cdot x_{4}+b_{5} \cdot x_{5}+b_{6} \cdot x_{6}+b_{7} \cdot x_{7} .
$$


Table 1. Matrix of experimental design and results.

\begin{tabular}{|c|c|c|c|c|c|c|c|c|c|c|c|c|c|}
\hline \multirow{3}{*}{ Years } & \multicolumn{8}{|c|}{$\begin{array}{l}\text { Input } \\
\text { factors }\end{array}$} & \multicolumn{5}{|c|}{ response functions } \\
\hline & & A & B & $\mathrm{C}$ & $\mathrm{D}$ & $\mathrm{E}$ & $\mathrm{F}$ & G & K & $\mathrm{L}$ & M & $\mathrm{N}$ & $\mathrm{W}$ \\
\hline & $x_{0}$ & $x_{1}$ & $x_{2}$ & $x_{3}$ & $x_{4}$ & $x_{5}$ & $x_{6}$ & $x_{7}$ & $Y_{1}$ & $Y_{2}$ & $Y_{3}$ & $Y_{4}$ & $Y_{5}$ \\
\hline 1999 & + & + & - & + & - & - & + & - & 89.7 & 8.32 & 8.63 & 7.32 & 2.02 \\
\hline 2000 & + & - & - & + & + & + & - & - & 109.87 & 4.77 & 8.38 & 7.76 & 1.56 \\
\hline 2001 & + & + & + & + & + & + & + & + & 111.91 & 4.34 & 8.41 & 7.13 & 1.85 \\
\hline 2002 & + & - & + & + & - & - & - & + & 109.57 & 6.82 & 7.33 & 8.55 & 1.3 \\
\hline 2003 & + & + & - & - & + & - & - & + & 108.31 & 3.92 & 8.51 & 8.04 & 1.60 \\
\hline 2004 & + & - & - & - & - & + & + & + & 113.84 & 4.15 & 8.57 & 8.78 & 1.36 \\
\hline 2005 & + & + & + & - & - & + & - & - & 111.75 & 4.55 & 8.18 & 7.76 & 1.72 \\
\hline 2006 & + & - & + & - & + & - & + & - & 113.5 & 3.98 & 8.32 & 8.80 & 1.56 \\
\hline 2007 & + & + & - & + & + & - & + & + & 112,4 & 4.15 & 8.12 & 8.02 & 1.68 \\
\hline 2008 & + & - & - & + & - & + & - & + & 119.87 & 3.77 & 8.28 & 5.76 & 1.57 \\
\hline 2009 & + & + & + & + & + & + & - & + & 101.91 & 5.34 & 8.31 & 9.13 & 1.75 \\
\hline
\end{tabular}

With the independent variables:

in dimensionless scale:

$$
\left\{\begin{array}{l}
\mathrm{Y}_{1}=108.55-25.64 \mathrm{x}_{1}-2.74 \mathrm{x}_{2}+1.90 \mathrm{x}_{3}+ \\
+4.195 \mathrm{x}_{4}+2.27 \mathrm{x}_{5}-3.12 \mathrm{x}_{6}+3.33 \mathrm{x}_{7} \\
\left(\mathrm{~F}=15.423, \mathrm{~F}_{0.05,10,3}=5.719\right) \\
\mathrm{Y}_{2}=5.11+0.34 \mathrm{x}_{1}+0.087 \mathrm{x}_{2}-0.7116 \mathrm{x}_{3}- \\
-0.851 \mathrm{x}_{4}+0.883 \mathrm{x}_{5}+0.341 \mathrm{x}_{6}+0.198 \mathrm{x}_{7} \\
\left(\mathrm{~F}=17.527, \mathrm{~F}_{0.05,10,3}=5.719\right) \\
\mathrm{Y}_{3}=8.293-1.146 \mathrm{x}_{1}+0.12 \mathrm{x}_{2}+0.078 \mathrm{x}_{3}+ \\
+0147 \mathrm{x}_{4}+0.142 \mathrm{x}_{5}+0.147 \mathrm{x}_{6}-0.90 \mathrm{x}_{7} ; \\
\left(\mathrm{F}=13.213, \mathrm{~F}_{0.05,10,3}=5.719\right) \\
\mathrm{Y}_{4}=8.027-0.121 \mathrm{x}_{1}-0.245 \mathrm{x}_{2}-0.0863 \mathrm{x}_{3}+ \\
+0.11 \mathrm{x}_{4}-0.0438 \mathrm{x}_{5}-0.121 \mathrm{x}_{6}+0.179 \mathrm{x}_{7} ; \\
\left(\mathrm{F}=12.417, \mathrm{~F}_{0.05,10,3}=5.719\right) \\
\mathrm{Y}_{5}=1.628-0.351 \mathrm{x}_{1}+0.098 \mathrm{x}_{2}+0.067 \mathrm{x}_{3}+ \\
+0.0098 \mathrm{x}_{4}+0.129 \mathrm{x}_{5}+0.007 \mathrm{x}_{6}-0.0218 \mathrm{x}_{7} \\
\left(\mathrm{~F}=29.658, \mathrm{~F}_{0.05,10,3}=5.719\right)
\end{array}\right.
$$

in the size scale:

$$
\left\{\begin{array}{l}
Y_{1}=162.72-1.71 A-0.48 B+0.014 C+0.2 \cdot 10^{-2} D+0.1 .10^{-2} E-0.3 \cdot 10^{-2} F+26.64 G \\
Y_{2}=-4.603+0.14 A+0.015 B-0.5 \cdot 10^{-2} C-0.04 \cdot 10^{-2} D+0.04 \cdot 10^{-2} E+0.35 \cdot 10^{-3} F+1.58 G \\
Y_{3}=14.358-0.048 A+0.02 B+0.6 \cdot 10^{-3} C+0.6 \cdot 10^{-4} D+0.7 \cdot 10^{-4} E+0.15 \cdot 10^{-3} F-7.2 G \\
Y_{4}=8.513-0.5 \cdot 10^{-2} A-0.043 B-0.7 \cdot 10^{-3} C+0.5 \cdot 10^{-4} D-0.2 \cdot 10^{-4} E-0.13 \cdot 10^{-3} F+1.48 G \\
Y_{5}=2.016-0.0149 A+0.017 B+0.5 \cdot 10^{-3} C+0.4 \cdot 10^{-5}+0.6 \cdot 10^{-4} E+0.007 \cdot 10^{-3} F-0.174 G
\end{array}\right.
$$

\section{RESULTS OF THE EXPERIMENT}

In planning and conducting experiments, the reproducibility, evaluation of the significance of the regression coefficients of the equation and the adequacy of the obtained relationships were tested (Alexeyev \& Levich. 1997), (Balzter, Braun \& Kohler. 1998). 
Verification of the experiment reproducibility was carried out on the dispersion of response functions defined for each planning row of the matrix. To verify the homogeneity of dispersions the Cochran's criterion was used. For these investigations the variance in lines and in total were calculated (Kremer. 2004), (Sovetov \& Yakovlev. 1999). To test the homogeneity of dispersions at significance level $\alpha=0.05$, the statistics $G_{\mathrm{v}}$ was calculated:

$$
G_{\mathrm{v}}=\frac{S_{y_{i \max }}^{2}}{\sum S_{y_{i}}^{2}}=0.376
$$

Compared with the critical values $G_{j-\alpha ; b}, q$, while $p=N-1=7, k=m-1=2$; table-valued $G_{1-0.05 ; 7,2}=0.7218$. Then $G_{v}=0.3765<G_{1-0.05 ; 7,2}=0.7218$, i.e. hypothesis about the accuracy of the measurements is not rejected.

Checking on adequacy is an estimate of the approximation errors and was performed using Fisher's ratio test for a given factor of significance $\alpha=0.05$. The calculated value of $F$ - statistics was found by the formulas:

$$
\begin{gathered}
F=\frac{S^{2}(Y)}{S_{\text {adqt }}^{2}} \\
S^{2}(Y)=\frac{\sum\left(Y_{i}-\hat{Y}_{i}\right)^{2}}{N-1} \\
S_{\text {adqt }}^{2}=\frac{\sum\left(Y_{i}-\hat{Y}_{i}\right)^{2}}{N-k}
\end{gathered}
$$

where $Y=$ wherein the arithmetic mean value of the dependent variable; = the value calculated by the equation variable; $s_{\text {adq }}^{2}=$ adequacy dispersion equation regression of experimental data; $S^{2}(Y)=$ the dispersion of the dependent variable.

For dependencies $Y_{1}-Y_{5}(8)$, the values $F_{i}>F_{0.05 ; 10 ; 3}=5.719$, i.e. the adequacy of the regression equations hypothesis is accepted (Kremer. 2004).

From the equations it follows that the independent variables on the degree of influence on the dependent parameters, taking into account boundary conditions adopted were ranked as follows, as shown in Table 2.

This shows that the greater influence on social and technological subsystem is made by air emissions, discharges into the aquatic environment and radioactive waste, and the least by domestic wastes.

Confidence intervals for the regression coefficients of equation (8) were calculated using the formula:

$$
\Delta S=\sqrt{S_{a d q t}^{2}} \cdot G_{i j}
$$

Table 2. Ranging, the absolute value of the regression coefficients, the degree of influence on the dependent parameters.

\begin{tabular}{ll}
$y_{1}$ & $x_{1}(\mathrm{~A})>x_{3}(\mathrm{C})>x_{7}(\mathrm{G})>x_{6}(\mathrm{~F})>x_{2}(\mathrm{~B})>x_{5}(\mathrm{E})>x_{4}(\mathrm{D})$ \\
$y_{2}$ & $x_{6}(\mathrm{~F})>x_{4}(\mathrm{D})>x_{3}(\mathrm{C})>x_{7}(\mathrm{G})>x_{1}(\mathrm{~A})>x_{2}(\mathrm{~B})>x_{5}(\mathrm{E})$ \\
$y_{3}$ & $x_{1}(\mathrm{~A})>x_{7}(\mathrm{G})>x_{6}(\mathrm{~F})>x_{4}(\mathrm{D})>x_{3}(\mathrm{C})>x_{2}(\mathrm{~B})>x_{5}(\mathrm{E})$ \\
$y_{4}$ & $x_{2}(\mathrm{~B})>x_{7}(\mathrm{G})>x_{1}(\mathrm{~A})>x_{6}(\mathrm{~F})>x_{4}(\mathrm{D})>x_{3}(\mathrm{C})>x_{5}(\mathrm{E})$ \\
$y_{5}$ & $x_{1}(\mathrm{~A})>x_{6}(\mathrm{~F})>x_{2}(\mathrm{~B})>x_{7}(\mathrm{G})>x_{3}(\mathrm{C})>x_{4}(\mathrm{D})>x_{5}(\mathrm{E})$ \\
\hline
\end{tabular}


where $t=$ table-valued Student's t-test for significance levels of 0.05 and the number of degrees of freedom $N-k ; G_{i j}=$ reverse-diagonal elements of the information matrix (XTX)-1.

Investigation on the presence of autocorrelation using Durbin-Watson statistics was performed. Calculation of the Durbin-Watson test showed:

$$
d_{1}=\frac{\sum_{i=1}^{n}\left(e_{i}-e_{i-1}\right)^{2}}{\sum_{i=1}^{n} e_{i}^{2}}=2.215
$$

$d_{2}=2.114 ; d_{3}=2.015 ; d_{4}=2.11 ; d_{5}=2.084$, since $d>2$, then there is no autocorrelation, therefore obtained models can be used as predictive (Kremer. 2004).

The identified linear mathematical models allow to analyze the nature of the emissions, to plan and make decisions in the development of measures to reduce the impact of technological and man-made factors on the social complex NIS.

With the help of the developed models, it is possible to conduct the forecast values of the $Y_{1}-Y_{5}$ and eventually choose efficient production technology and processing of useful minerals.

Calculation of the Durbin-Watson test:

$$
d_{1}=\frac{\sum_{i=1}^{n}\left(e_{i}-e_{i-1}\right)^{2}}{\sum_{i=1}^{n} e_{i}^{2}}=\frac{5998.124}{2736.788}=2.191
$$

Since $d>2$, then there are no alternatives to the existence of autocorrelation negative autocorrelation. From the table defined for $n=27, k=2$ (the number of explanatory variables) and the significance level $a=0.05: d_{1}=1.24$ and $d_{2}=1.56$. Since $4-d=1.809>d_{2}=1.56$ therefore there is no autocorrelation.

Eliminating autocorrelation 1 - order generalized least squares method.

The covariance matrix of the vector of regression residuals was built. Then find its assessment and build a model of GLS. The random variables are investigated $\varepsilon_{i}$ :

$$
M\left[\varepsilon_{i}\right]=k \sum_{k=0}^{\infty} \rho \mathbf{M}\left[\delta_{i-k}\right]=0
$$

Dispersion of regression excesses is a permanent value:

$$
\begin{gathered}
D\left[\varepsilon_{i}\right]=\sigma_{0}^{2} \frac{1}{1-\rho^{2}} \\
\sum \varepsilon=\frac{\sigma_{0}^{2}}{1-\rho^{2}}\left(\begin{array}{cccc}
1 & \rho & \ldots & \rho^{n-1} \\
\rho & 1 & \ldots & \rho^{n-2} \\
\ldots & \ldots & \ldots & \ldots \\
\rho^{n-1} & \rho^{n-2} & \ldots & \rho^{n-k}
\end{array}\right)
\end{gathered}
$$

Thus, the type of the covariance matrix of the vector of regression excesses was specified. To estimate the GLS regression coefficients the matrix was constructed. Using the form $\Sigma$, can be specified $\Omega$. 


$$
\Omega=\frac{1}{1-\rho^{2}}\left(\begin{array}{cccc}
-\rho & 1 & -\rho & 0 \\
0 & -\rho & 1 & -\rho \\
\ldots & \ldots & \ldots & \ldots \\
0 & -\rho & 1 & -\rho
\end{array}\right)
$$

In practice, the value $\rho$ is unknown. The method of assessing using the Cochrane-Orcutt method, which is an iterative approach that includes the following steps:

1. The GLS regression was assessed: $Y=X^{T} b$;

2. The excesses were calculated $e_{i}^{(1)}$;

3. The regression dependence of $e_{i}$ on $e_{i-1}$ was assessed: $e_{i}=\rho^{(1)} e_{i-1} \delta_{i}, e_{i-1}$ is the coefficient of assessment, it represents an estimate $\rho^{(i)}$,

4. $\Omega^{(1)}$ was built. The regression dependence of $Y$ on $X$ GLS was assessed using this matrix.

5. Re-calculated, $e_{i}$ the process is returned to step 3 .

The process ended when $\rho^{(i)}$ the values of the last and the penultimate stages became about the same.

After the analysis were identified anomalous values. The separation of inhomogeneous sample collections was produced. The assessment of influence degree of various factors on the nature of the variability of the properties of objects of natural and industrial systems is given. It was found that in particular NIS health is mostly affected by emissions into the atmosphere, lithosphere, and hydrosphere. These factors must be considered when choosing the safe production and processing technology, in terms of the negative impact on public health.

Taking into account the obtained dependence $Y_{6}$, influence dependencies of anthropogenic factors on the social and technological subsystem NIS will take the form:

$$
\left\{\begin{array}{l}
Y_{1}=108.55-2.27 x_{1}-2.74 x_{2}+1.90 x_{3}+4.195 x_{4}+25.64 x_{5}-3.12 x_{6}+3.33 x_{7} \\
Y_{2}=5.11-0.34 x_{1}-0.087 x_{2}+0.7116 x_{3}-0.851 x_{4}+0.198 x_{5}-0.341 x_{6}+0.883 x_{7} \\
Y_{3}=8.293-0.147 x_{1}+0.12 x_{2}+0.078 x_{3}+1.146 x_{4}+0.142 x_{5}-0.147 x_{6}+0.90 x_{7} \\
Y_{4}=8.027-0.121 x_{1}-0.0438 x_{2}-0.0863 x_{3}+0.11 x_{4}-0.245 x_{5}-0.121 x_{6}+0.179 x_{7} \\
Y_{5}=1.628-0.3511 x_{1}+0.098 x_{2}+0.067 x_{3}+0.0098 x_{4}+0.129 x_{5}+0.0071 x_{6}-0.0218 x_{7} \\
Y_{6}=-14.9+14.4 x_{1}+4.0 x_{2}+0.906 x_{3}+0.174 x_{4}+0.237 x_{5}
\end{array}\right.
$$

For the equation $Y_{6}-F_{0.05 ; 10 ; 3}=5.719$;

$F=15.423>F_{0.05} ; 10 ; 3$, i.e. the adequacy of the regression equations hypothesis is accepted.

Investigation on the autocorrelation using Durbin-Watson statistic was done (21): $d_{1}=$ $2.215 ; d_{2}=2.114 ; d_{3}=2.015 ; d_{4}=2.11 ; d_{5}=2.084 ; d_{6}=2.191$.

Since $d>2$, therefore, there is no autocorrelation, so these models can be used as predictive (Kremer. 2004), (Spitsnadel. 2002), (Jorgensen. 1976), (Belov. 2003).

\section{CONCLUSION}

With the help of the developed models, it is possible to conduct the forecast values of the $Y_{1}-Y_{6}$ and choose effective technology of mining and processing of useful minerals. Identified linear mathematical models enable reasonably plan and make organizational and technical solutions in the development of measures to reduce the impact of technological and man-made factors in the social and technological NIS subsystem.

The influence assessment of anthropogenic factors on the social and technological subsystem faculty of mining and processing complex is conducted. The revealed dependences allow to analyze the nature of the emissions, to plan and make decisions in the development of measures to reduce the impact of technological and man-made factors on the social and technological NIS subsystem. 
The correlation and regression dependences of anthropogenic factors influence of production subsystem on social subsystem of NIS are developed.

The conducted studies made it possible to use the developed methods and models for ensuring sustainable development of mountainous territories.

\section{REFERENCES}

Alexeyev, V.L. \& Levich, A.P. 1997. A search for maximum species abundances in ecological communities under conditional diversity optimization. Bull. of Mathemat. Biology 59: 649-677.

Balzter, H., Braun, P.W. \& Kohler, W. 1998. Cellular automata models for vegetation dynamics. Ecological Modeling 107: 113-125.

Belov, P.G. 2003. System analysis and modeling of hazardous processes in the technosphere. Moscow: Publishing Center Academy.

Bendoricchio, G. \& Jorgensen, S.E. 1997. Exergy as a goal function of ecosystems dynamic. Ecological modeling 102: 5-15.

Birch, L.O. 1979. The effect of species of animals which share common resources on one another's distribution and abundance. Fortschr. Zool. 25: 197-221.

Boer, P.J. 1980. Exclusion or coexistence and the taxonomic or ecological relationship between species. Neth. J. Zool. 30: 278-306.

Bosikov, I.I., Klyuev, R.V., Revazov, V.Ch. \& Pilieva, D.E. 2018. Performance evaluation of functioning of natural-industrial system of mining-processing complex with help of analytical and mathematical models. IOP Conference Series: Materials Science and Engineering 327.

Jorgensen, S.E. 1976. A eutrophication model for a lake. J. Ecol. model 2: 147-165.

Klyuev, R.V., Bosikov, I.I., Gavrina, O.A., \& Revazov, V.Ch. 2018. System analysis of power consumption by nonferrous metallurgy enterprises on the basis of rank modeling of individual technocenosis castes. MATEC Web Conf. 226. (2018) 04018. EDP Sciences.

Kremer, N.S. 2004. Theory of Probability and Mathematical Statistics. Moscow: UNITY DANA.

Saaty, T. L. 1986. Axiomatic foundation of the analytic hierarchy process. Management Science 32: 841-855.

Sovetov, B.Y. \& Yakovlev, S.A. 1999. Modeling systems. Moscow: Higher School.

Spitsnadel, V.N. 2002. Theory and practice of optimal decision making. St. Petersburg: Publishing house Business press.

Yegorova, E.V., Klyuev, R.V., Bosikov, I.I. \& Tsidaev, B.S. 2018. Evaluation of use of effective technologies for increasing sustainable development of natural and technical system of oil and gas complex. Sustainable Development of Mountain Territories 3(37): 392-403. 